\title{
Designing and Measuring the Hot-Embossing Machine with Hybrid Positioning Functions
}

\author{
Cheng-Hsien Wu, Cheng-Hao Chiu \\ Department of Mold \& Die Engineering, National Kaohsiung University of Science and Technology, Kaohsiung County
}

\begin{abstract}
The demands of the ability of industrial automotive production are rising. The precision positioning is the most important among the manufacturing and measuring. Molds might result in making equipment deviations via poor accuracies on mass production because of the poor design and front processing. It influences the qualities of products, or damages the mold themselves. Based on the Hot-Embossing process, the study designed a set including the Hot-Embossing machine with platform for positioning system holding the mold. The positioning and adjusting function, with $\mathrm{X}, \mathrm{Y}, \mathrm{C}$ axis, separates the Hot-Embossing machine from the traditional one.

Taken smart phone case as the experimental designed concept and verified the pressing molds with the final thickness with the before and after correction for lengths, wide, and the error values of horizontal symmetry to investigate the accuracies of positioning capability. Then, verifying the Hot-Embossing machine from reconstruction of the product.
\end{abstract}

\section{Introduction}

Most of the products which made from high polymer materials are in need of molds to be shaped. After designing and machining, however, the molds allowed the error accuracy in the components of parts. The problem of inaccurate position would only occur when tolerances does in assembling. Take producing dual -sided microstructure as an example; the reducing of the product functionalities might result in dual-sided positioning error via assembly tolerances[1]. As shown in figure 1, the dual-sided micro lens array, the original design is the double-sided aliquots arrangement. After operating, however, the excessive concentration of light diffused distribution occurs because the dislocation of dual-sided structure via position error as shown in figure 2, the light distribution of the dislocation of dual-sided micro lens array.

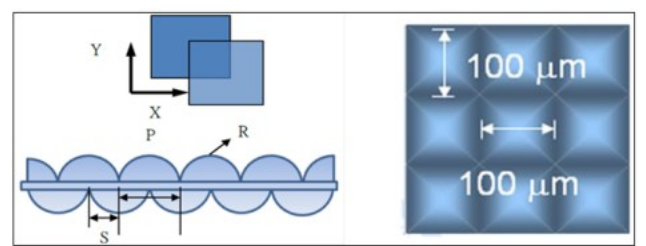

Figure 1. Sketch map of dual-sided micro lens array
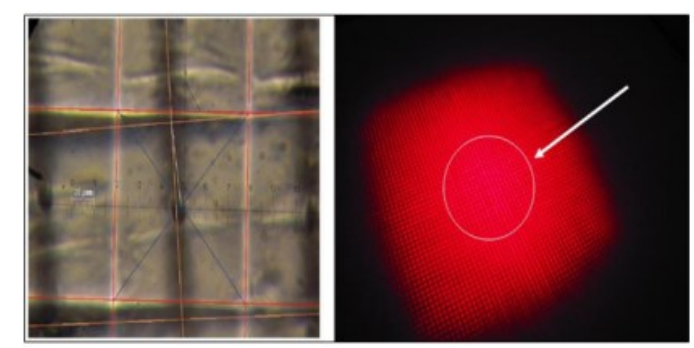

Figure 2. Light distribution of the dislocation of dual-sided micro lens array

To solve the problem above, it has to disassemble molds, re-position, and reassemble; or vary molds. The process would not be just one time. This reduces the efficiency, increases cost, takes times, and influences capacity. Therefore, designing one loader which could adjust immediately after testing can solve the problem efficiently. There are many patents and literatures on studying the function of positioning platform; and utilizing external loader for Hot-Embossing process. It is because the lack attentions of positioning ability on Hot-Embossing machine in industry. Thus, the study designed a micro Hot-Embossing machine based on Hot-Embossing and to economize space, disassemble and assemble easily, simplifies mechanical structure, operate easily, and include precision positioning capability. Taking thin-shell molding as the experience demonstrates the positioning accuracy and reconstruction for the relative study in the future. 


\section{Experiment}

\subsection{Design concept and demand}

A precise Hot-Embossing machine, shown in Fig. 3, is specially designed for the accurate replication of optical elements. The Hot-Embossing is calibrated and adjusted to improve its alignment and parallelism. A loaded cell was applied to monitor the pressing force. The measured force was also used to control the embossing at a specified pressing force. Four cartridge heaters were applied to heat the plates. Two heaters were installed in the upper plate and the other two were installed in the lower plate. These four cartridge heaters were controlled by two thermocouples installed in the two plates. The temperatures of the two plates were averaged and made use of controlling the mold temperature. Another thermocouple was installed on top of the polymer substrate to monitor the material temperature. The Hot-Embossing was regularly calibrated and adjusted to improve its alignment and parallelism.

\subsection{Hot-embossing machine and $X-Y$ horizontal positioning and adjusting platform}

The basic demands for making a Hot-Embossing machine are dynamics, structure and function, and control. According to the theory above, setting the Hot-Embossing machine with hybrid position functions in the study as one combines the features of relative process and the lacks of tradition one. The basic structure chart in figure 3 is the technical architecture for the study. The sketch map of perspective view of the machine and the assembly horizontal slider are shown in figure 4 and 5.

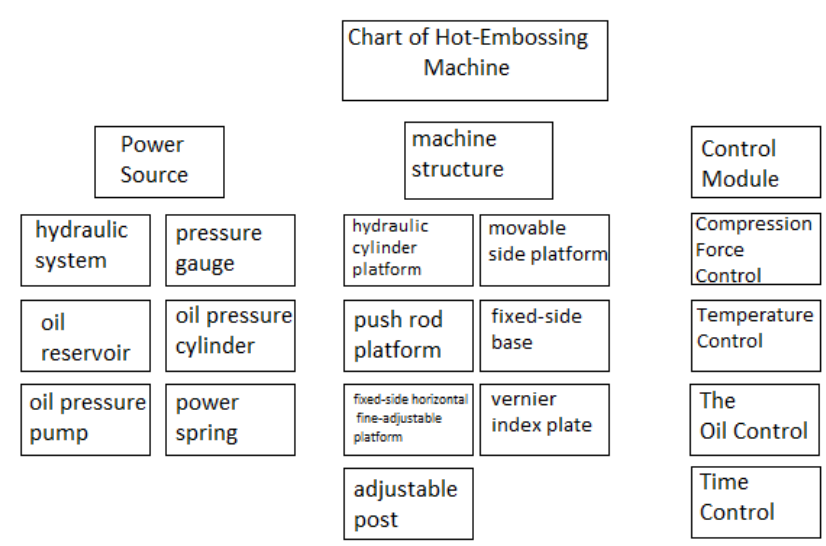

Figure 3. Technical architecture of Hot-Embossing machine with the hybrid positioning function

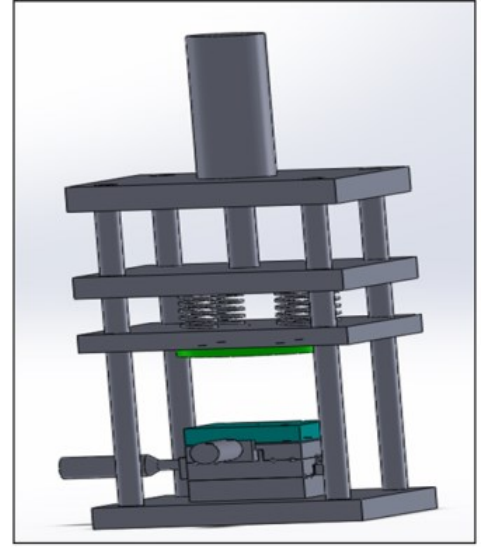

Figure 4. Sketch map of Hot-Embossing machine with hybrid positioning function

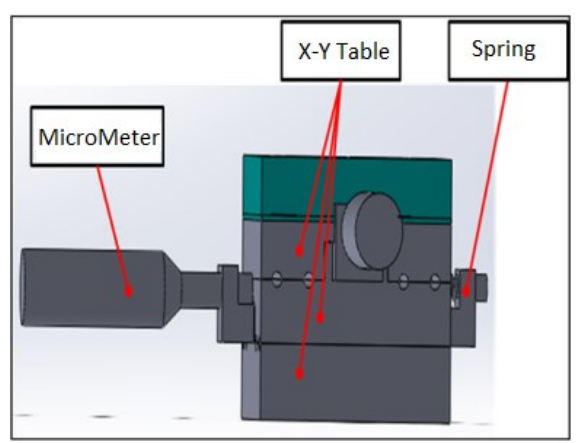

Figure 5. Sketch map of assembly horizontal slider

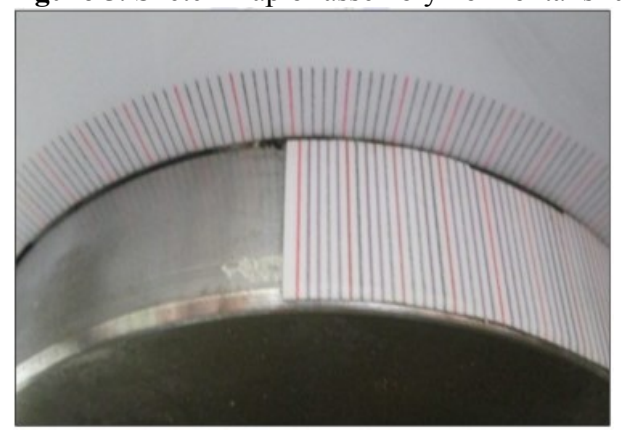

Figure 6. Analytical scale table and real installed photo

\subsection{Rotary positioning platform}

As figure 6, the rotary spinner platform is combined with main scale fixed tray and venier scale turntable. Using steel S50C supports the high load. According to the universal protractor theory, divided the main scale fixed tray from 1 degree of each section, and the venier scale turntable into 30 equal parts with 29 degrees of main scale fixed tray in each part, which means that each venier scale section is 0.97 degree. While the first engraving line of venier scale aim at the 0 degree of main scale fixed tray, both of them will have a gap in 0.03 degree. The resolution of rotary positioning platform will be 2' after unit transforming. To lighter the weight of machine, the study gear the tray and turntable via movable screw with bearing fasten through guide pillars and side board. 


\subsection{Experience procedures}

The design processes of the study are as follow:

I. Assembling and designing machine

II. Proofing stabilities of forming machine

III. Proofing stabilities of positioning system

IV. Proofing actual product

\subsection{Design of experimental molds}

In order to manufacturing a shell product with height, depth, and width; the experience utilized FDAC steel to devise a closed Hot-Embossing mold. it utilize its measuring values of the side thickness to revise the positioning system of Hot-Embossing machine and to devise the adjusting capability and function of it.

As shown in figure 7, the under mold can separate into two shelf. First, the lower fixed plate is to fixed the under molds and the main structure of positioning system. The second shelf is the down template, it is made by high precision machining to combine the insert and template. The three penetrating horizontal holes are used to set up electrical bars $(\varnothing 10 \mathrm{~mm})$ and temperature sensors $(\varnothing 5 \mathrm{~mm})$, also the cooling channel and waterways connector thread (ø8mm).

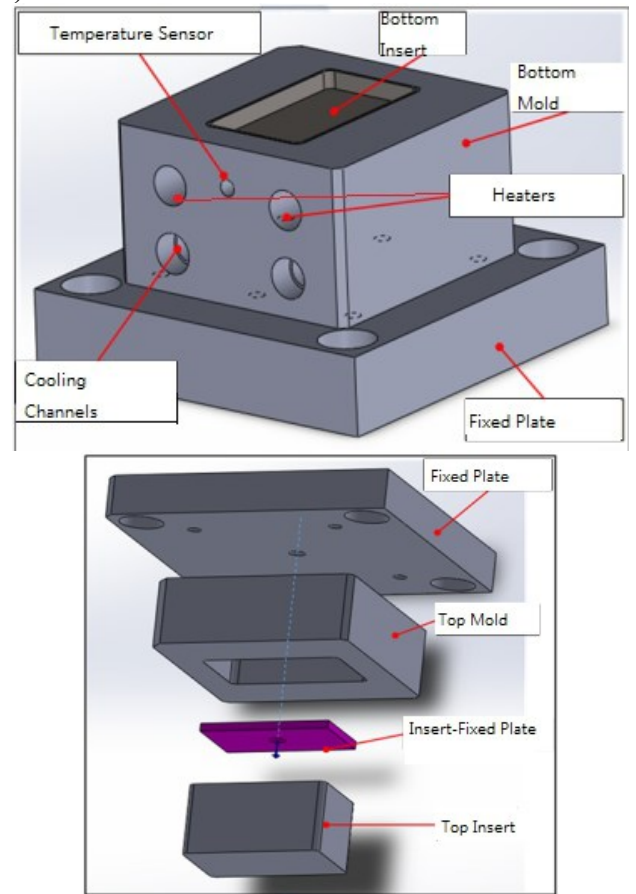

Figure 7. Sketch map of down molds (left) and up molds (right)

\section{Results}

Hot-Embossing machine with hybrid positioning function developed according to the theories shown as figure 8 mentioned above. It is conducted experimental test respectively. The test will focus on excluding the abilities to adjust horizontal axis $\mathrm{X}-\mathrm{Y}$, rotation angle axis $\mathrm{C}$, and the reproduction, also the disadvantages of product and forming characteristics.

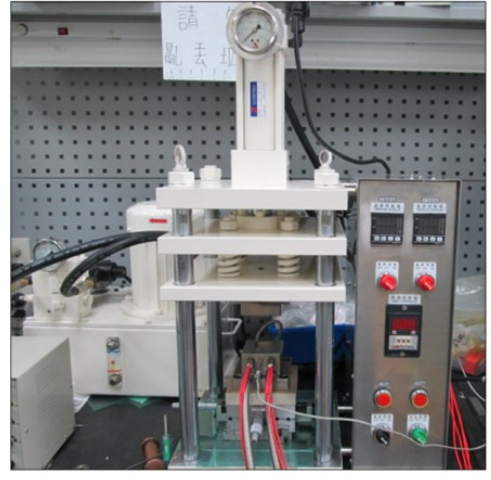

Figure 8. Hot-Embossing machine with hybrid positioning function and oil pressure system

\subsection{Steps and parameters of testing positioning technique}

The steps of the positioning technique of Hot-Embossing machine are as follow:

I. Setting the up molds and down molds respectively on the rotary platform and horizontal platform of Hot-Embossing machine with hybrid positioning function.

II. Taking the polymer materials properly via $\rho=M / \square$, density volume quality and quantity formulation, and putting into the down insert.

III. Making by Hot-Embossing process: preheat, Hot-Embossing, cooling, open

IV. Utilizing OM measures preliminarily to confirm if the product is in the right position via optical electron microscope (OEM).

V. Utilizing OM measures to confirm it again via OEM VHX-1000 and recording the data.

The polymer materials, PMMA, which was used in the study, were produced by CHIMEI Corporation. Parameters, shown in table-1, were set according to Yao[2] and Heckele[3]. Demonstrating angles adjust; there are 6 groups of data in total, adjusting 12 ' in each time. Then, demonstrating horizontal adjusts; there are 20 groups of data, adjusting axis $\mathrm{X}$ and $\mathrm{Y} 9$ times separately based on 30 $\mu \mathrm{m}$ in each adjustment. Demonstrating reproduction of product in the third part, the 12 relative positions on the four sides of product surveyed the relation of thickness, as shown in figure 9.

Table 1. Experimental parameters in testing positioning technique

\begin{tabular}{|l|c|c|c|}
\hline & $\begin{array}{c}\text { Temperature } \\
\left({ }^{\circ} \mathrm{C}\right)\end{array}$ & $\begin{array}{c}\text { Compression } \\
(\mathrm{kgf})\end{array}$ & Time(s) \\
\hline Pre-Embossing & 160 & 700 & 60 \\
\hline Hot-Embossing & 160 & 2900 & 900 \\
\hline Cooling & 65 & 2900 & 60 \\
\hline
\end{tabular}




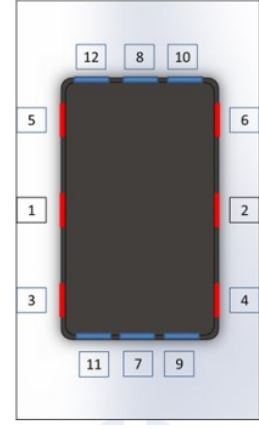

Figure 9. Sketch map of measured position of reconstruction verification

\subsection{Result of testing positioning technique}

Adjusting process of product measurement is shown in Table 2.

I. By OEC VHX-1000, the angle positioning test result is as follow:

II. First Hot-Embossing testing of C-axis, the angle value is 89.65 degrees. The value was 89.90 degrees after first adjusting. Following is 90.09 degrees. The third is 90.26 degrees. Next is 90.49 degrees. It is 90.71 degrees after the fifth adjusting.

III. By OEC VHX-1000, the $\mathrm{X}$ axis positioning test [4]result is as follow:

IV. First Hot-Embossing testing of $\mathrm{X}$-axis, the value is $690.13 \mu \mathrm{m}$. After first adjusting, the value was $719.85 \mu \mathrm{m}$. Following is $747.44 \mu \mathrm{m}$. The third is $779.29 \mu \mathrm{m}$. Next is $809.03 \mu \mathrm{m}$. It is $838.73 \mu \mathrm{m}$ after the fifth adjusting. Then, it is $870.75 \mu \mathrm{m}$ at the sixth adjusting. Following is the $900.43 \mu \mathrm{m}$. Next is $930.10 \mu \mathrm{m}$. Final, the ninth adjusting is $959.80 \mu \mathrm{m}$.

V. By OEC VHX-1000, the Y axis positioning test result is as follow:

VI. First Hot-Embossing testing of $\mathrm{Y}$ axis, the value is $747.44 \mu \mathrm{m}$. After first adjusting, the value was $775.03 \mu \mathrm{m}$. Following is $804.78 \mu \mathrm{m}$. The third is $834.51 \mu \mathrm{m}$. Next is $864.31 \mu \mathrm{m}$. It is $894.03 \mu \mathrm{m}$ after the fifth adjusting. Then, it is $925.88 \mu \mathrm{m}$ at the sixth adjusting. Following is the $955.63 \mu \mathrm{m}$. Next is $985.36 \mu \mathrm{m}$. The ninth adjusting, the value comes to $1014.97 \mu \mathrm{m}$. Table 2 is the analysis of this result.

Reiteration of the product is verified by the thickness of mold around edges which settle on $800 \mu \mathrm{m}$ at one edge, $1600 \mu \mathrm{m}$ at two edges. The marked position in figure 9 gauged the relative thickness of production. The summation is shown in Table 3.
Table 2. Analysis table of result of adjusting process of product

\begin{tabular}{|c|c|c|c|c|c|c|}
\hline & $\begin{array}{c}\mathrm{X} \text {-axis } \\
(\mu \mathrm{m})\end{array}$ & $\begin{array}{c}\text { Alignment } \\
\text { Error with } \\
\text { Last time }\end{array}$ & $\begin{array}{c}\text { Y-axis } \\
(\mu \mathrm{m})\end{array}$ & \begin{tabular}{|c|} 
Alignme \\
nt Error \\
with \\
Last \\
time \\
\end{tabular} & C-axis & $\begin{array}{c}\text { Alignme } \\
\text { nt Error } \\
\text { with Last } \\
\text { time }\end{array}$ \\
\hline $\begin{array}{l}\text { Pre- } \\
\text { Pos. }\end{array}$ & 690.13 & & 747.44 & & $89.65 \circ$ & \\
\hline 1 & 719.85 & 29.72 & 775.03 & 27.59 & $89.9 \circ$ & $0.25 \circ$ \\
\hline 2 & 747.44 & 27.59 & 804.78 & 29.75 & $90.09 \circ$ & $0.19 \circ$ \\
\hline 3 & 779.29 & 31.85 & 834.51 & 29.73 & $90.26 \circ$ & $0.17 \circ$ \\
\hline 4 & 809.03 & 29.74 & 864.31 & 29.8 & $90.49 \circ$ & $0.23 \circ$ \\
\hline 5 & 838.73 & 29.7 & 894.03 & 29.72 & $90.71 \circ$ & $0.22 \circ$ \\
\hline 6 & 870.75 & 32.02 & 925.88 & 31.85 & & \\
\hline 7 & 900.43 & 29.68 & 955.63 & 29.75 & & \\
\hline 8 & 930.1 & 29.67 & 985.36 & 29.73 & & \\
\hline 9 & 959.8 & 29.7 & 1014.97 & 29.61 & & \\
\hline & AVG & 29.96 & AVG & 29.72 & AVG & $0.21 \circ$ \\
\hline & \begin{tabular}{|c|} 
Adjust \\
ment \\
Accura \\
cy \\
\end{tabular} & $99.80 \%$ & $\begin{array}{c}\text { Adjustm } \\
\text { ent } \\
\text { Accurac } \\
\mathrm{y}\end{array}$ & $99.00 \%$ & $\begin{array}{c}\text { Adjust } \\
\text { ment } \\
\text { Accur } \\
\text { acy } \\
\end{array}$ & $105 \%$ \\
\hline & $\begin{array}{l}\text { Alignm } \\
\text { ent } \\
\text { Error } \\
\end{array}$ & $-0.20 \%$ & $\begin{array}{c}\text { Alignme } \\
\text { nt } \\
\text { Error } \\
\end{array}$ & $-1 \%$ & $\begin{array}{c}\text { Align } \\
\text { ment } \\
\text { Error } \\
\end{array}$ & $+5 \%$ \\
\hline
\end{tabular}


Table 3. Analysis table of product reconstructions

\begin{tabular}{|c|c|c|c|}
\hline \multicolumn{4}{|l|}{ Y-axis } \\
\hline Point.1 & Point.2 & Total & $\begin{array}{l}\text { Alignment } \\
\text { Error }\end{array}$ \\
\hline 949.15 & 662.83 & 1611.98 & \begin{tabular}{|l|}
11.98 \\
\end{tabular} \\
\hline Point.3 & Point.4 & Total & \begin{tabular}{|l|} 
Alignment \\
Error
\end{tabular} \\
\hline 955.71 & 671 & 1626.71 & 26.71 \\
\hline Point.5 & Point.6 & Total & $\begin{array}{l}\text { Alignment } \\
\text { Error }\end{array}$ \\
\hline 951.27 & 662.51 & 1613.78 & 13.78 \\
\hline \multicolumn{4}{|l|}{$\mathrm{X}$-axis } \\
\hline Point.7 & Point.8 & Total & \begin{tabular}{|l|} 
Alignment \\
Error
\end{tabular} \\
\hline 770.81 & 840.86 & 1611.67 & 11.67 \\
\hline Point.9 & Point.10 & Total & \begin{tabular}{|l|} 
Alignment \\
Error
\end{tabular} \\
\hline 768.66 & 840.86 & 1609.52 & 9.52 \\
\hline Point.11 & Point.12 & Total & \begin{tabular}{|l} 
Alignment \\
Error
\end{tabular} \\
\hline 772.91 & \begin{tabular}{|l|}
838.74 \\
\end{tabular} & \begin{tabular}{|l|}
1611.65 \\
\end{tabular} & 11.65 \\
\hline \multicolumn{2}{|c|}{$\begin{array}{c}\text { Design of Sidewall } \\
\text { Thickness(T) is } 1600 \mu \mathrm{m} \text { for } \\
\text { Mold-insert }\end{array}$} & \begin{tabular}{|l|} 
Average \\
Alignment \\
Error \\
\end{tabular} & 14.21 \\
\hline
\end{tabular}

\subsection{Steps of applying positioning technique}

The prospect inspired by cell phone shell, we want to design a shell product with even thickness in four edges. It is because the uneven symmetry of shell might result in the deviations of angles and horizontal positioning. The uneven symmetry might occur the situations of defective assembly or unable to assemble.

The steps of applying positioning technique are as follow:

I. Settling the mold on the Hot-Embossing machine that develops in this prospect.

II. Beginning the first Hot-Embossing, and measuring the thickness and the angular deviation of product

III. Doing the one-off positioning on the measured angular deviation. After it, the angle should be positioned, and do the Hot-Embossing again.

IV. Surveying the thickness deviation on four edges after second Hot-Embossing, and doing the one-off horizontal axis positioning on the deviation. After one-off adjustment, the thickness should be right and could begin the third Hot-Embossing.

Gauging the thickness of four edges after one-off adjustment and seeing if fill the conclusion of positioning technique mention above.

\subsection{Results of applying positioning technique}

As shown in figure 10(a), the initial Hot-Embossing angular measured value is $89.65^{\circ}$ which has $0.35^{\circ}$ error compared with the expectation $90^{\circ}$. The error would be $21^{\text {' }}$ after unit transforming. Since the minimum amounts that are able to adjusted is smaller than 2', the designing resolution of positioning platform, thus the default adjusting value set as $22^{\prime}$. It is shown in figure 11(b); gauging the value after one adjusting is $90.03^{\circ}$, which actually move $22.78^{\prime}$ after unit transforming. It has $0.78^{\prime}$ error, which is $0.013^{\circ}$ error after unit transforming.

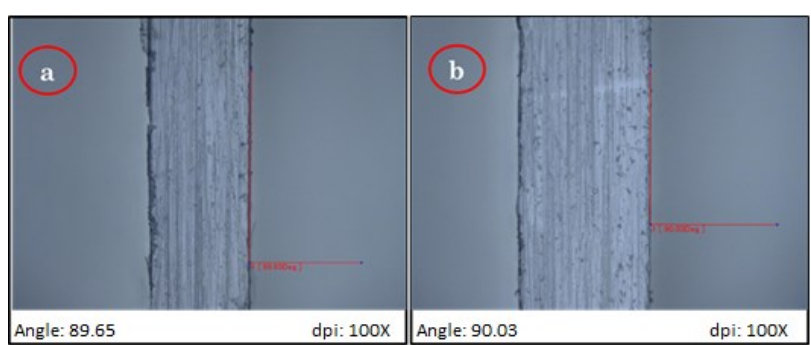

Figure 10.(a)Initial angular measurement of hot-embossing (b) Angular measurement after one adjusting

As shown in figure 11(a) and (b), the thickness of shell on $\mathrm{X}$ axis is $643.47 \mu \mathrm{m}$ after angular adjusting, $\mathrm{Y}$ axis is $953.40 \mu \mathrm{m}$. Hence, a deflection error $156.53 \mu \mathrm{m}$ compare with expected value $800 \mu \mathrm{m}$ on $\mathrm{X}$ axis, and a deflection error $153.40 \mu \mathrm{m}$ compare with expected value $800 \mu \mathrm{m}$ on $\mathrm{Y}$ axis. Since the minimum amounts that are able to adjusted is smaller than $10 \mu \mathrm{m}$, the designing resolution of positioning platform, thus the default adjusting value set as $160 \mu \mathrm{m}$ on $\mathrm{X}$ axis and $150 \mu \mathrm{m}$ pm $\mathrm{Y}$ axis. It is shown in figure 11(c) and (d); gauging the $\mathrm{X}$ axis directive measurement value after one horizontal adjusting is 804.76 $\mu \mathrm{m}$, which actually move $161.29 \mu \mathrm{m}$ after unit transforming. On the other hand, $\mathrm{Y}$ axis directive measurement value is $804.76 \mu \mathrm{m}$ after one horizontal adjusting is $804.76 \mu \mathrm{m}$, which actually move $148.64 \mu \mathrm{m}$ after unit transforming.

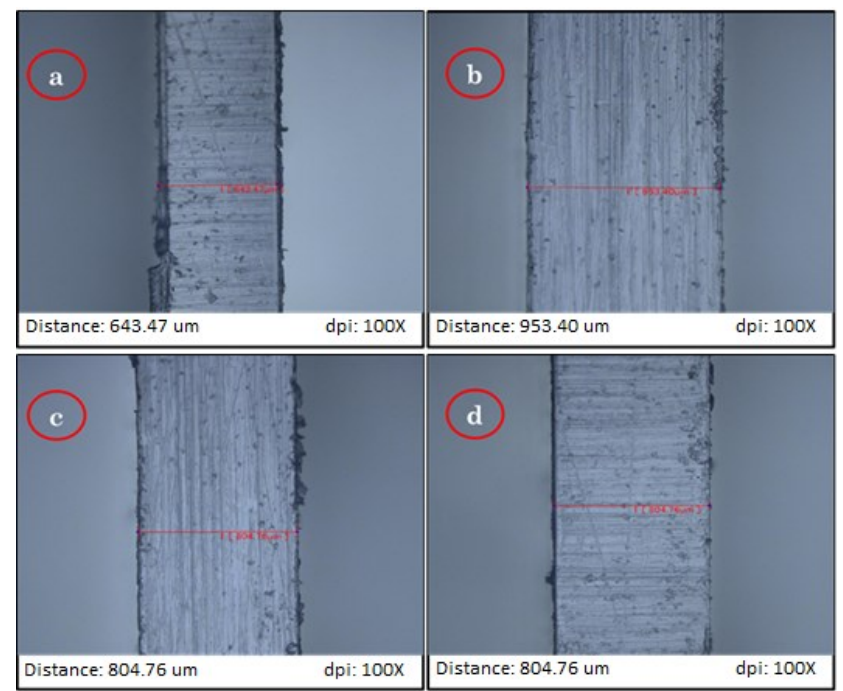

Figure 11. (a) Initial measured value of $X$ axis thickness (b) Initial measured value of $Y$ axis thickness (c) $\mathrm{X}$ axis thickness after one adjusting (d) Y axis thickness after one adjusting

\subsection{Analyze the influences of hot-embossing pressures to the product}

The shell production, which was produced in the experience, was made from acrylic particles. The set is $50 \mathrm{~mm} \times 30 \mathrm{~mm} \times 5 \mathrm{~mm}$, the thickness of four edges is set as $0.8 \mathrm{~mm}$, and the bottom thickness is set as $0.5 \mathrm{~mm}$. It is a structure with height, depth, width. Settle a group of parameters of Hot-Embossing pressures to discuss the influences in process of making product from granular 
materials, and discuss the result via surface structures that observed by OEM.

Form 4 is the parameters setting in the experience. Among it, time for preheating is 60 seconds, temperature for preheating is $160^{\circ} \mathrm{C}$, and pressures for preheating is $700 \mathrm{~kg}$. Besides, time of keeping pressures is 60 seconds, temperature for keeping pressures is $65^{\circ} \mathrm{C}$, and pressures for keeping pressures is $2900 \mathrm{kgf}$. Furthermore, time for Hot-Embossing is 900 seconds, and temperature for Hot-Embossing is $160^{\circ} \mathrm{C}$. Main testing parameters of Hot-Embossing were separated into 4 groups.

\subsection{Analyze the parameters of hot-embossing pressures}

As shown in figure 12, when the Hot-Embossing pressures were set in $1700 \mathrm{kgf}$, the depth and width traces of crystalline phase on the surface are obvious. In addition to crystallizations could not complete welding, the product could not be shaped.

As shown in figure 13, when the Hot-Embossing pressures were set in 2000kgf, the depth and width traces of crystalline phase on the surface were smaller than the first prospect. The welding between crystallization is higher. The product had an embryo of shaping.

As shown in figure 14, when the when the Hot-Embossing pressures were set in $2300 \mathrm{kgf}$, the depth and width traces of crystalline phase on the surface were presented as tiny lines. The ratios of lines were significantly reduced on the product area. The heights of four edges were nearly to the forming altitude.

As shown in figure 15 when the Hot-Embossing pressures were set in $2300 \mathrm{kgf}$, the depth and width traces of crystalline phase on the surface were quite slight. The ratios of lines were unapparent on the product area.

According to the experiences above, choosing granular materials on making a product with height, depth, and width with specific high temperature, thought the high temperature is helpful for crystallizations to be heated and distorted, the deficiency of Hot-Embossing pressures will make the crystallizations too loose to weld, furthermore, inadequate strength will bring defects on the product or unable to shape because the materials are not able to go deep into insert. From the experience, the long sides, which have short distance with the mid, had good flow, on the other hand, the short sides, which were far away from mid, had clear drop.

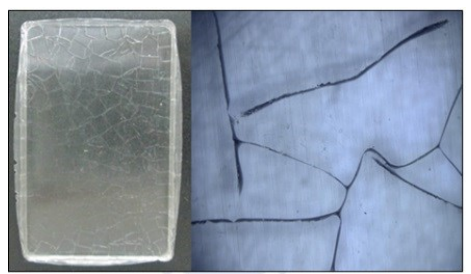

Figure 12. Result of 1700kgf Hot-Embossing

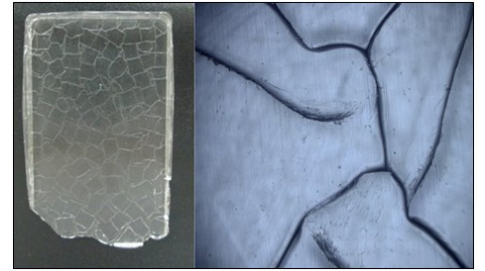

Figure 13. Result of 2000kgf Hot-Embossing

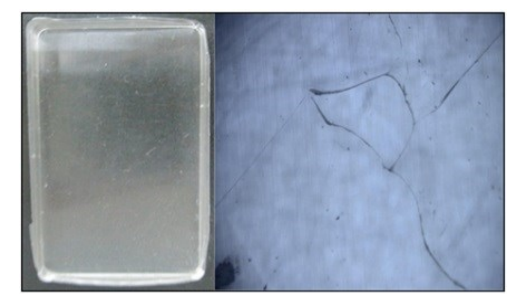

Figure 14. Result of 2300kgf Hot-Embossing

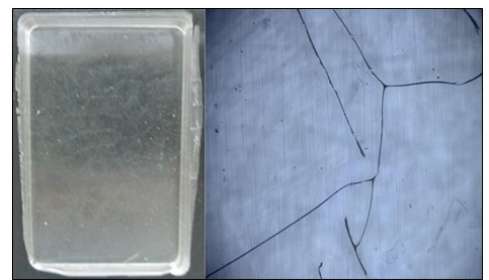

Figure 15. Result of 2600kgf Hot-Embossing

\subsection{Analyze the influences of hot-embossing time to defects on the surface}

Among parameters setting in the experience, time for preheating is 60 seconds, temperature for preheating is $160^{\circ} \mathrm{C}$, pressures for preheating is $700 \mathrm{~kg}$. Besides, time of keeping pressures is 60 seconds, temperature for keeping pressures is $65^{\circ} \mathrm{C}$, and pressures for keeping pressures is 2900kgf. Furthermore, time for Hot-Embossing is 900 seconds, and temperature for Hot-Embossing is $160^{\circ} \mathrm{C}$. Main testing parameters of Hot-Embossing were separated into 4 groups.

\subsection{Analyze the parameters of hot-embossing time}

As shown in figure 16, when the Hot-Embossing time set as 600 seconds, the surface average roughness value (Ra) is $0.22 \mu \mathrm{m}$, average roughness depth (Rz) is $2.06 \mu \mathrm{m}$, and the gap between the maximum and the minimum value (Rdc) is $5.37 \mu \mathrm{m}$.

As shown in figure 17, when the Hot-Embossing time set as 900 seconds, the surface average roughness value (Ra) is $0.21 \mu \mathrm{m}$, average roughness depth $(\mathrm{Rz})$ is $1.37 \mu \mathrm{m}$, and the gap between maximum and minimum value (Rdc) is $1.80 \mu \mathrm{m}$.

As shown in figure 18, when the Hot-Embossing time set as 1200 seconds, the surface average roughness value (Ra) is $0.23 \mu \mathrm{m}$, average roughness depth (Rz) is $1.38 \mu \mathrm{m}$, and the gap between maximum and minimum value (Rdc) is $1.73 \mu \mathrm{m}$.

As shown in figure 19, when the Hot-Embossing time set as 1500 seconds, the surface average roughness value (Ra) is $0.20 \mu \mathrm{m}$, average roughness depth (Rz) is $1.10 \mu \mathrm{m}$, and 
the gap between maximum and minimum value ( $\mathrm{Rdc}$ ) is $1.50 \mu \mathrm{m}$.

From the result above, Hot-Embossing time has tiny influence upon the roughness of surface appearances, which means that the surface is still smoothness in a certain extent. The inadequate time for crystallizations to weld completely when the shortness of Hot-Embossing time according to figure 16. On the other hand, too much time for crystallizations welding will make the bad appearances, like the residual glue, to the product. It is because the heating and cooling systems were not designed in up mold, the temperature difference cause the residual glue only happened at the side of up mold.

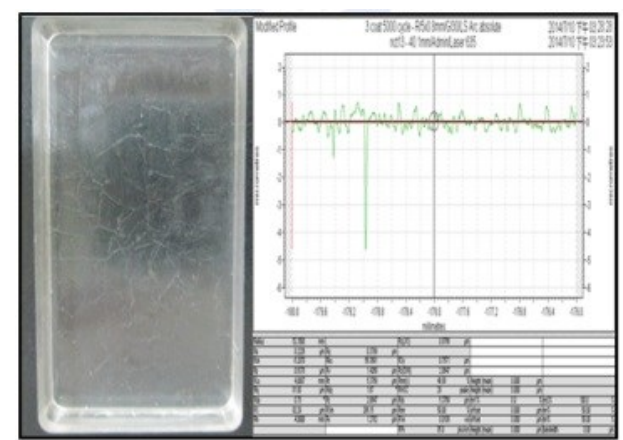

Figure 16. Result of 600 seconds Hot-Embossing

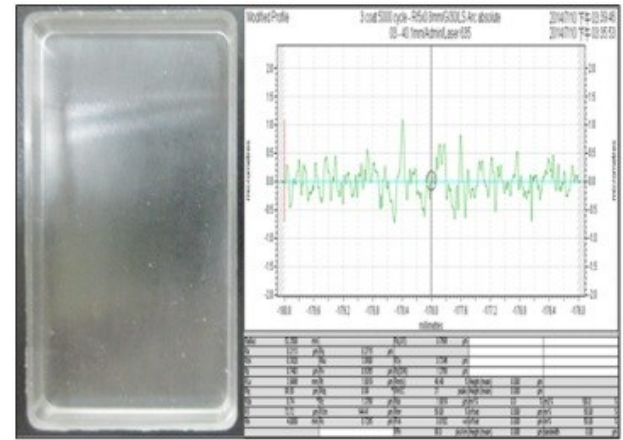

Figure 17. Result of 900 seconds Hot-Embossing

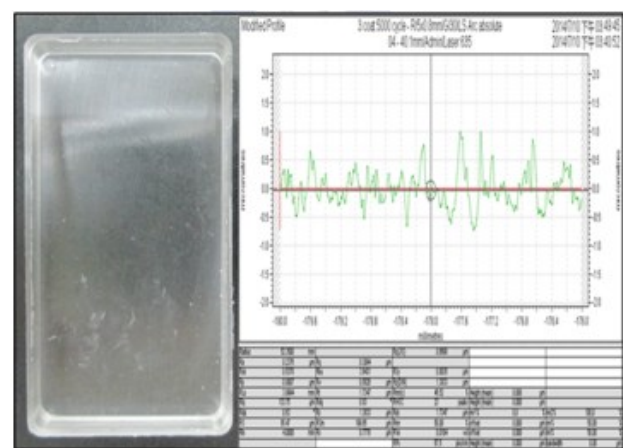

Figure 18. Result of 600 seconds Hot-Embossing

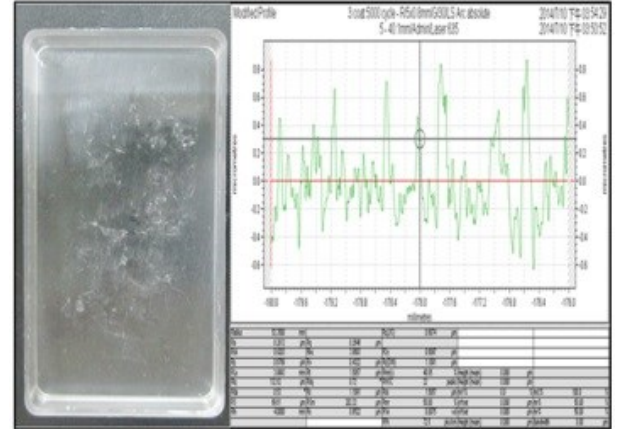

Figure 19. Result of 900 seconds Hot-Embossing

\subsection{Analyze the pressure residual stress}

According to figure 20, detecting the shell product in the experience through photoelastic instruments would find the low residual stress of product in Hot-Embossing process. There is only $5.37 \mathrm{~nm}$ in average photoelastic value and $2.68 \mathrm{MPa}$ for average stress value. Thus the warps on product in Hot-Embossing are obscure.

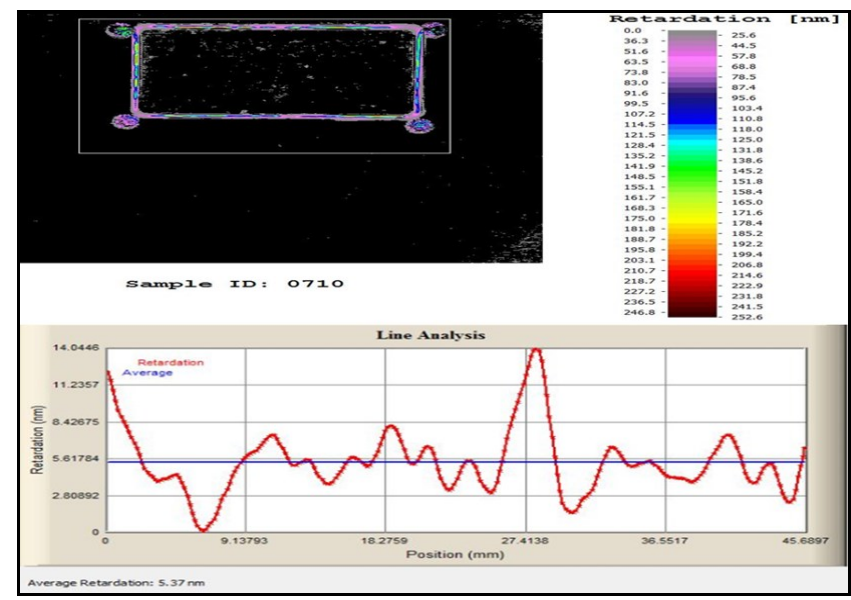

Figure 20. Analysis diagram of residual stress of shell product

\section{Discussions and results}

\subsection{Conclusions for testing positioning technique}

Setting $30 \mu \mathrm{m}$ for each adjustment on $\mathrm{X}$ axis, the average adjusting process is $29.96 \mu \mathrm{m}$, and the positioning accuracy is $99.80 \%$. Then setting $30 \mu \mathrm{m}$ for each adjustment on $\mathrm{Y}$ axis, the average adjusting process is $29.72 \mu \mathrm{m}$, and the positioning accuracy is $99.00 \%$. Setting $12^{\prime}, 0.2^{\circ}$, for each rotation adjustment on $\mathrm{C}$ axis, the average adjusting process is $0.21^{\circ}$, and the positioning accuracy is $105 \%$. The average error between actual measured value and theory value is only $14.21 \mu \mathrm{m}$ on the reconstruction of product.

\subsection{Conclusions for applying positioning technique}

The value of actual movement on angle is $22.78^{\prime}$ after one-off adjustment; it had a $0.78^{\prime}$ ' error compare with the adjusting value forecast 22 '. It is 2 ' smaller than setting 
resolution. The value of actual movement on horizontal $\mathrm{X}$ axis is $161.29 \mu \mathrm{m}$ after one-off adjustment; it had a $1.29 \mu \mathrm{m}$ error compare with the adjusting value forecast $160 \mu \mathrm{m}$. It is $10 \mu \mathrm{m}$ smaller than setting resolution. And the value of actual movement on horizontal $\mathrm{Y}$ axis is $148.64 \mu \mathrm{m}$ after one-off adjustment; it had a $1.36 \mu \mathrm{m}$ error compare with the adjusting value forecast $160 \mu \mathrm{m}$. It is $10 \mu \mathrm{m}$ smaller than setting resolution. It can prove that the Hot-Embossing machine with hybrid positioning functions which built in the experience is confirmed to the result of positioning and adjusting technique mentioned above after one-off positioning adjusting capability. It possesses the ability of speedy adjusting and positioning.

\section{Conclusion}

The study combined the features of Hot-Embossing process, positioning techniques, and wafer packaging together; also referred to the literature review to design and develop the Hot-Embossing machine with hybrid positioning functions. Then, evidences of its abilities are gained in the experiences. Comparing to the dual-side positioning plat form of Chiu[5], the accuracies are much more improved. Positioning accuracies of $\mathrm{X}$ axis directions from $77.47 \%$ achieved to $99.80 \%, \mathrm{Y}$ axis directions from $90.47 \%$ to $99.00 \%$ under the process with relative media which could bring errors and the factors of manual operation. Also, positioning accuracy of $\mathrm{C}$ axis direction which utilized principle of vernier caliper achieved $105 \%$ from $100.02 \%$. Among them, the combination of $\mathrm{C}$ axis rotary table and movable side board reduced the volume and weight significantly. Only the angular adjusting resolutions still has deviations after angle and rotation unit transforming. Also, because the scale table is transferred on the circumference of turntable, it needs the conversion from formula. Therefore, the tiny gaps between adjusting value would accumulate. Besides, according to the product and average error from testing of reconstructions are only 14.21 , which the average ration of reproduction is $98.57 \%$, it can actual apply in Hot-Embossing process via characteristic of strong spring parallel.

\section{References and notes}

1. Cheng-Hsien Wu, Cheng-Hao Chiu, "Hot Embossing with Two-Axis Micro-Positioning for Double-Sided Microstructures", Advanced Science Letters, Vol.4, pp. 1308-1311 (2011).

2. D. Yao and B. Kim, J. Micromech. Microeng. 12, 604 (2002).

3. M. Heckele, W. Bacher and KD Müller, Microsystem Technologies 4, 122 (1998).

4. Cheng-Hsien $\mathrm{Wu}$ and Hsien-Chang Kuo, Journal of Mechanical Science of Technology 21(10), 1338 (2007).

5. Cheng-Hsien $\mathrm{Wu}$, Cheng-Hao Chiu, "Research and Development about Error Analysis of Hot-Embossing for Double-Sided Microstructures", The 2nd International Symposium on Hybrid Materials and Processing(2011) October 26-29; Busan, Korea. 